\title{
The inlluence of one-sided extraneous stimulation on directional walking while blindfolded
}

\author{
HOWARD R. GRUMPELT, DONNA E. HARRIS, and MARILYN WALLACE \\ Bureau of Research, N.J. Neuro-Psychiatric Institute, Princeton, N.J. 08540 \\ and \\ Washington College, Chestertown, Ind. 21620
}

To test a hypothesis from sensory-tonic field theory, 18 students looked at a cross $52 \mathrm{ft}$ away and, after being blindfolded, were given the task of attempting to walk directly to the cross while simultaneously receiving stimulation from a vibrator on the left or the right side of the neck or receiving no stimulation. Compensatory movement away from the side of stimulation was found.

Wener \& Wapner (1952) have proposed that sensory and tonic systems interact and establish some kind of equilibrium in a functioning organism. Confirmation has been found in extraneous stimulation and in body tilt experiments for the view that weighting either the sensory or the tonic system results in compensatory adjustments in the other system (Wapner, Werner, \& Chandler, 1951; Wapner \& Werner, 1952; Bauermeister, Werner, \& Wapner, 1964). However, work has apparently not been performed on movement through space toward a goal when strongly stimulating one side of the body. The current authors predicted that Ss who looked at a distant point, were blindfolded, and then attempted to walk to that point while receiving strong right- or left-sided kinesthetic, tactual, and auditory stimulation from a vibrator would deviate to the side opposite that stimulated, as compared to movement when no such stimulation was provided.

$$
\text { METHOD }
$$

Eighteen Ss, 7 males and 11 females from the introductory psychology class, volunteered for the study. The experiment was conducted in an $83 \times 48 \mathrm{ft}$ gymnasium. A painted foot outline was used to position Ss in a standard manner. Each $S$ was told to look at a cross and then, after being blindfolded and either stimulated or not, to attempt to walk directly to the cross. The cross was made of black electrical tape, $8 \times 6 \frac{1}{2}$ in., and was placed on a white bulletin board $52 \mathrm{ft}$ away. Ss were shown a string stretched across the room at chest height, $2 \mathrm{ft}$ in front of the bulletin board, that stopped them from bumping into the board or going past it. A small vibrator, ordinarily used for giving a massage, was encased in a styrofoam box with only the vibrating head exposed, and this box was attached to the neck and shoulder regions of the $S$ by rubber straps. The box was carved to fit the shoulder. The vibrating head pressed against the S's neck. The vibrator was attached to $75 \mathrm{ft}$ of electrical cord, and this cord was strapped to the center of the S's back. The encased vibrator provided auditory, kinesthetic, and tactual stimulation. Each $S$ received four trials under left-sided stimulation, four under right-sided stimulation, and four under no stimulation. The vibrator was attached to the back of the neck for the no-stimulation condition, but it was not turned on for the trial. All of the possible six combinations of order of stimulation (left, right, or none) were employed equally, and a table of random numbers determined which order a specific $\mathbf{S}$ would receive.

When the $S$ reached the string hung across the room, the vibrator was turned off, a weighted cord was attached around his neck, and a measurement was taken, to $1 / 10$ in., of the distance from the cross to the point of stopping. The $S$ was then returned and positioned again at the starting point before the blindfold was removed and another trial begun. No information was relayed as to how close the $\mathrm{S}$ had come to the cross. In order to avoid having to deal with negative numbers, all scores were transformed by adding the constant 280 in. to each, this constant being 3 in. larger than the largest deviation to the left (original minus value). A mean of the measurements for the four trials on each condition was obtained prior to further analysis of the data.

\section{RESULTS}

A randomized-blocks analysis of variance revealed that treatments were significant beyond the .001 level ( $d f=2 / 34, F=12.05)$. The means and estimates of population standard deviations for each of the treatment groups were: right stimulation, $\frac{2}{X}=257.3$ in., $\quad S D=35.7$ in.; no stimulation, $\quad \bar{X}=282.1$ in., $\mathrm{SD}=17.0 \mathrm{in} . ;$ and left stimulation, $\bar{X}=301.0$ in., $\mathrm{SD}=29.7$ in. Duncan's multiple range test indicated that all oi the differences between the means were significant beyond the .05 level of confidence. Cochran's test indicated that the hypothesis of homogeneity of variances could not be rejected, although $\mathrm{C}$ was close to the .05 level $(\mathrm{df}=3 / 17, \mathrm{C}=.521)$.

\section{CONCLUSIONS}

Results of the analysis of variance and Duncan's multiple range test provide support for the hypothesis that weighting the body with stimulation on one side produces deviations toward the opposite side when a $S$ attempts to walk blindfolded in a straight line to a distant point. This finding lends further credence to Werner \& Wapner's (1952) contention that sensory and tonic aspects of functioning interact to establish an equilibrium.

\section{REFERENCES}

BAUERMEISTER, M., WERNER, H., \& WAPNER, $S$. The effect of body tilt on tactual-kinesthetic perception of verticality. American Journal of Psychology, 1964,77, 451-456.

WAPNER, $S$, \& WERNER, H. Experiments on sensory-tonic field theory of perception: V. Effect of body status on the kinesthetic perception of verticality. Journal of Experimental Psychology, $1952,44,126-131$

WAPNER, S., WERNER, H., \& CHANDLER, K. A. Experiments on sensory-tonic field theory of perception: I. Effect of extraneous stimulation on the visual perception of verticality. Journal of Experimental Psychology, 1951, 42, 341-345.

WERNER, H., \& WAPNER, S. Toward a general theory of perception. Psychological Review, 1952, 49, 324-338. 